\section{No Decelerated $\beta$-Decay of Tritium Solved in Titanium}

\section{Ewald Wicke}

Institut für Physikalische Chemie der Universität, Schloßplatz 4, D-48149 Münster

Z. Naturforsch. 49a, 1259-1261 (1994);

received December 13, 1994

Experimental results on the interaction of tritium with fine particles of titanium, published in Phys. Lett. A and attributed to decelerated $\beta$-decay of tritium solved in titanium, are instead explained by adsorption of tritium on the surface of the particles, formation of tritium oxide when oxygen is present, and normal $\beta$-decay.

In one of the latest issues of Physics Letters, O. Reifenschweiler, retired Chief Physicist of Philips Research Laboratories, published a paper [1] on "Reduced radioactivity of tritium in small titanium particles", describing research work done at Eindhoven about 30 years ago. In the discussion of the experimental results, two states of tritium are mentioned: The gaseous state and tritium absorbed in the lattice of the titanium particles. In no case, however, the existence of a third state of tritium, i.e. as adsorbate at a solid surface, for instance at $\mathrm{Ti}$, has been taken into account. That this state played an enormes role in the experiments becomes clear from a simple calculation.

The process of producing the titanium particles has been described [1] in the following way: "In our experiments the titanium preparation was made by evaporation of the metal in argon at a suitable pressure, e.g. 0.5 to $2 \mathrm{~cm} \mathrm{Hg}$. It was deposited as a kind of soot, consisting of monocrystalline particles about $15 \mathrm{~nm}$ in diameter, arranged in chains, on the inner wall of the measuring vessel.... After the argon was pumped out, the tritium was added and was completely absorbed within a few seconds."

In the experiment described first, a layer of $48 \mathrm{mg} \mathrm{Ti}$ was prepared in this way. The applied quantity of $\mathrm{Ti}$, $10.8 \mathrm{~mm}^{3}$ (density $\varrho_{\mathrm{Ti}}=4.43 \mathrm{~g} \mathrm{~cm}^{-3}$ ) equals $6.5 \times 10^{15}$ spherical particles of $15 \mathrm{~nm}$ diameter, presenting a surface of $4.15 \mathrm{~m}^{2}$. A monolayer on this surface corresponds to about $4.15 \times 10^{19}$ tritium atoms, or $0.07 \mathrm{mmol}$. An amount of $48 \mathrm{mg} \mathrm{Ti}$, on the other hand, is nearly $1 \mathrm{mmol} \mathrm{Ti}$. Therefore, a monolayer of tritium

Reprint requests to Prof. E. Wicke. atoms on the surface of the small $\mathrm{Ti}$ particles corresponds to a compound of $\mathrm{TiT}_{0.07}$. Since this experiment was done with $\mathrm{TiT}_{0.0035}$, the capacity of a monolayer on the Ti surface was by about a factor 20 higher (!).

The course of this investigation was, to add $0.0035 \times 1 / 2 \mathrm{mmol} \mathrm{T}_{2}$ to the layer of $1 \mathrm{mmol} \mathrm{Ti}$ single crystals at room temperature, and then to heat up the system - under continuously pumping out - to temperatures just above $400^{\circ} \mathrm{C}$. The $\beta$-activity of the tritium was determined by measuring the $\mathrm{X}$-radiation, accompanying the $\beta$-decay (bremsstrahlung and characteristic X-rays) by a GM-tube. The number of GMcounts per second is

$$
n=\alpha \lambda N_{\mathrm{T}}
$$

where $N_{\mathrm{T}}$ is the number of tritium atoms, $\lambda$ their decay constant, and $\alpha$ the counting efficiency of the GMtube, which was at the beginning of the experiment determined to be $\alpha=4.2 \times 10^{-9}$.

In Fig. 1 the counts per min are plotted versus the temperature $\mathrm{T}$ of the system, showing in curve $\mathrm{A}$ the results of this heating experiment. Curve B displays the pressure of the released tritium gas when heating up the system under closed condition. There occurs a reduction of the counting rate from the initial value down to $72 \%$ at $160{ }^{\circ} \mathrm{C}$ and to $60 \%$ at $275^{\circ} \mathrm{C}$. Thereafter the counting rate comes up again to the initial value at about $360^{\circ} \mathrm{C}$, and then falls down steeply to the background value. $O$. Reifenschweiler interprets this reduction of the counting rate as a decrease of the decay constant $\lambda$ in (1) and develops for this a nuclear pair hypothesis [1] which he himself, indeed, characterizes as "highly unorthodox".

Taking into account the adsorbed state of tritium, the explanation of Fig. 1 can be given as follows. A few seconds after adding tritium into the gas room of the system at normal temperature, the tritium is adsorbed at the titanium surface, the count rate and the efficiency, $\alpha$, have their initial values. These values stay constant, until around $115^{\circ} \mathrm{C}$ tritium atoms begin to enter the lattice of the Ti particles. The distribution of the tritium now changes by diffusion, and the counting efficiency decreases owing to the difference of the bremsstrahlung in the Ti lattice compared to the free gas room above the Ti surface, and owing to the absorption of the $\mathrm{X}$-radiation by the Ti. The reduction of the counting rate, attributed by $\mathrm{O}$. Reifenschweiler to 


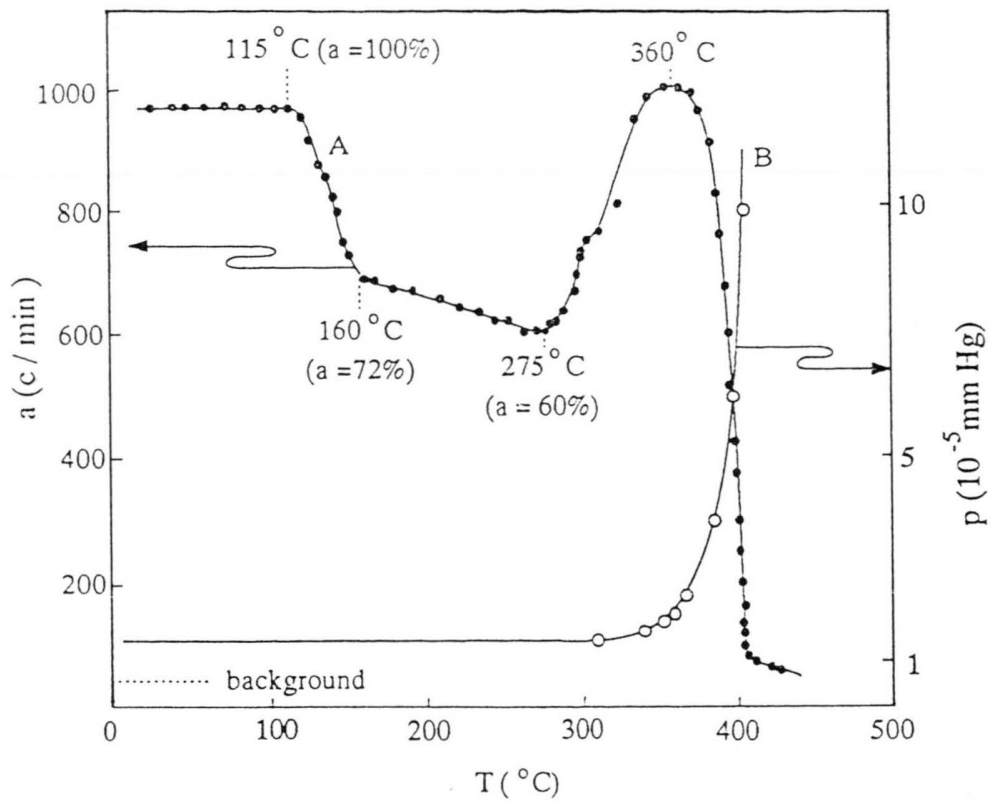

Fig. 1. Graph A: Count rate as a function of temperature in the pumped system. Graph B: Tritium pressure as a function of temperature in the closed system (reproduced from [1]).

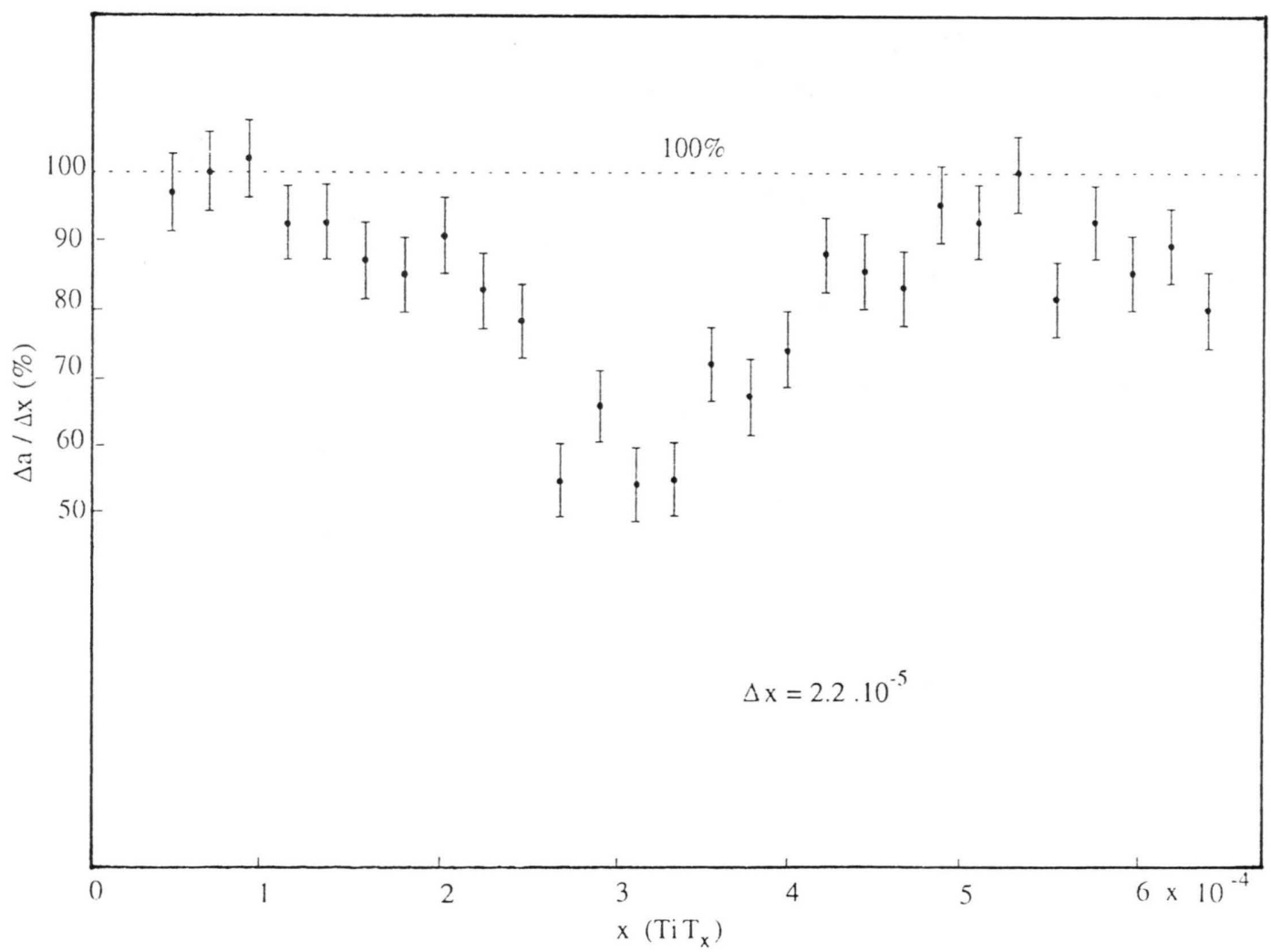

Fig. 2. Increase of radioactivity $\Delta a / \Delta x$ as a function of concentration $x$. Evaporator removed (reproduced from [1]). 
a decrease of the decay constant $\lambda$ of the tritium, is explained here by a decrease of the counting efficiency $\alpha$ as a result of the change in the distribution of the tritium.

At temperatures higher than about $300^{\circ} \mathrm{C}$ the $\mathrm{Ti}-\mathrm{T}$ system begins to decompose, $\mathrm{T}_{2}$ molecules are released from the Ti surface, and the radioactivity, after having recovered shortly the initial value, falls off steeply as the consequence of the loss of tritium.

The results of a second series of experiments, made isothermally at room temperature by adding successive quantities $\Delta x$ of tritium to $\mathrm{TiT}_{x}$ systems [1], can also be explained by the activity of adsorbed layers of tritium. In this case, only $3.6 \mathrm{mg}$ of Ti were deposited as finely divided particles on a gold layer at the inner wall of the measuring glass vessel, and the $\beta$-decay of the tritium was followed by a special electrometer device.

The amounts of tritium, added successively in these $\operatorname{TiT}_{x}$ experiments, were very small $\left(\Delta x=2.2 \times 10^{-5}\right)$, see Figure 2. Of prime importance in this case is, however, that the evaporator of the Ti was removed from the glass vessel prior to the first addition of tritium, and on this occasion impurities, especially oxygen, will have had access to the freshly deposited Ti layer. The first additions of tritium, adsorbed at the surface of the small Ti particles, will form OT-groups at the centers of this oxygen impurity, but will display full radioactivity in the electrometer, see the left side of Fig. $2(100 \%)$. The next additions $\Delta x$ of tritium will form more and more $\mathrm{T}_{2} \mathrm{O}$; this will desorb from the $\mathrm{Ti}$ surface and migrate to the glass wall, where $\mathrm{T}_{2} \mathrm{O}$ is more strongly adsorbed than at a metal surface. By this migration, however, parts of the tritium will no more be catched fully by the electrometer device. Therefrom the decrease in the measured growth of radioactivity of the later additions of tritium, down to about $55 \%$ at $x=3 \times 10^{-4}$, see Figure 2 . After further additions of tritium, the Ti surface will be more and more free of oxygen, hence the successive increase of the measured radioactivity, Fig. 2, up to the initial value of $100 \%$.

In this way, all somewhat puzzling results of the different series of experiments described in [1] can be explained by well-known and normal effects, and it seems not to be necessary to develop a new hypothesis on any change in the decay constant of tritium.

[1] O. Reifenschweiler, Physics Letters A 184, 149 (1994). 


\section{Erratum}

M. Baake, Small Oscillations, Sturm Sequencies, and Orthogonal Polynomials, Z. Naturforsch. 49a, $445-457$ (1994).

The following misprints have been overlooked in the stage of proofreading. The first line after Eq. (35) should refer to (34) rather than to (35). In Eqs. (47) and (49), $\widetilde{B}_{n}$ is the matrix of (48). The restriction of the first summation in (53) is $j \neq i$ instead of $j \neq j$.

In Appendix C, two corrections are necessary. In the first line after Eq. (73), the BogoljubovValatin transformation should read

$$
a_{k}=\frac{1}{2} \sum_{j}\left(\frac{\Phi_{k j}+\Psi_{k j}}{2} d_{j}+\frac{\Phi_{k j}+\Psi_{k j}}{2} d_{j}^{+}\right)
$$

while the second half of (74) should be

$$
\Phi_{k}(A-B)=\eta_{k} \cdot \Psi_{k} .
$$




\section{Sachverzeichnis}

Das Sachverzeichnis umfaßt Originalarbeiten, Notizen (N), und Errata

\section{Biophysik}

Application of a Miniaturised Probe for the Acquisition of Dielectric Data in Living Systems

S. Kohlsmann, M. Hetscher, and K. Kramer

1165

\section{Cluster}

Investigation of the Zero-Field Splitting of $\mathrm{d}^{8}$ Ions in Pseudo-tetragonal Ni(II) Compounds

J.-J. Chen, M.-L. Du, and Z.-M. Li

Pair Formation of Free Nucleobases and Mononucleosides in the Gas Phase

M. Dey, J. Grotemeyer, and E. W. Schlag

Size-dependent Trends in the Scattering of Small

Potassium Clusters by Water Molecules

A. Goldbach, F. Hensel, and K. Rademann

1013

Diffusion und Ionenleitung in Flüssigkeiten und Festkörpern

Internal Cation Mobilities in Molten $(\mathrm{Ca}, \mathrm{Ba}) \mathrm{Cl}_{2}$ H. Matsuura and I. Okada

Point Defects and Diffusion in Paratellurite

J. Wegener, O. Kanert, R. Küchler, and A. Watterich

\section{Elektrochemie}

Dissociation Degree of $\mathrm{HSO}_{4}^{-}$and Mean Ionic Activity Coefficient of Aqueous Sulfuric Acid of Different Molalities up to $473 \mathrm{~K}$ and 975 bar

B. A. Bilal and E. Müller

Potential of the Aqueous $\mathrm{Ag}-\mathrm{Ag}_{2} \mathrm{SO}_{4}$ Electrode in $1 \mathrm{~m} \mathrm{Na}_{2} \mathrm{SO}_{4}$ in Contact with $1 \mathrm{~m} \mathrm{H}_{2} \mathrm{SO}_{4}$ at up to $473 \mathrm{~K}$ and 975 bar . . $\quad$ B. A. Bilal and E. Müller

\section{Festkörper, amorph}

Investigation of the Structure of Amorphous Substances by Means of Electron Diffraction

J. Ankele, J. Mayer, P. Lamparter, and S. Steeb The Structure of Amorphous Platinum Disulfide as Studied by Anomalous X-ray Scattering

M. Saito, M. Wakeshima, N. Sato, T. Fujino, Y. Waseda, E. Matsubara, and K. T. Jacob Coordination of $\mathrm{Eu}^{3+}$ Ions in a Phosphate Glass by X-ray Diffraction

M. P. Medda, G. Piccaluga, G. Pinna, M. Bettinelli, and G. Cormier

\section{Festkörper, kristallin}

On the Enclathration of $\mathrm{NaB}(\mathrm{OH})_{4}$ in the $\beta$-Cages of Sodalite: Crystallization Kinetics and Crystal Structure . . . . . J. Ch. Buhl, C. Mundus, J. Löns, and W. Hoffmann Neutron Diffraction Study of 1,2,3-Trichlorobenzene-d $_{3}$. . . D. Groke, G. Heger, B. P. Schweiss, and $\mathrm{Al}$. Weiss Crystal Structure of Trimethylammonium Perchlorate in Three Solid Phases Including the Ionic Plastic Phase Obtainable above $480 \mathrm{~K}$

H. Ishida, Y. Kubozono, S. Kashino, and R. Ikeda Mössbauer Studies of Nickel-Iron Hydrotalcites U. Pegelow, M. Winterer, B. D. Mosel, M. Schmalz, and R. Schöllhorn Anharmonic Self-Consistent Theory of Crystals. II. The 2d and 3d Quartic Crystal Models

S. Sh. Soulayman, C. Ch. Marti, and $\mathrm{Ch}$. Ch. Guilpin

\section{Flüssige Kristalle}

On the Microscopic Stress Tensor for Anisotropic Molecules in Homogeneous Systems

A. Chrzanowska and K. Sokalski The Origin of the Helial Twist Inversion in Single Component Cholesteric Liquid Crystals

I. Dierking, F. Giesselmann, P. Zugenmaier, K. Mohr, H. Zaschke, and W. Kuczynski Dielectric Relaxation in Nematic and Isotropic Phases of 4-(trans-4'-n-Propylcyclohexyl)isothiocyanatobenzene . . . . J. Jadżyn, L. Hellemans,

M. Stockhausen, C. Legrand, and G. Czechowski Dilatometric Study of the Isotropic-Smectic F Transition of 100.14 . . N. V. S. Rao, G. P. Rani, D. M. Potukuchi, and V. G. K. M. Pisipati Dielectric Studies on Liquid Crystals under High Pressure: VI. Low Frequency Relaxation Process in the Nematic and Smectic A Phase of 4-n-Octyl-4'Cyanobiphenyl (8 CB)

S. Urban, T. Brückert, and A. Würflinger

\section{Flüssigkeiten}

X-Ray Diffraction Study of Methanol-Water Mixtures . . I. Bakó, G. Pálinkás, and K. Heinzinger Intraionic Structure of $\mathrm{HSO}_{4}^{-}$and Alkali Cation Configuration in Molten $\mathrm{NaHSO}_{4}$ and $\mathrm{KHSO}_{4}$

K. Fukushima, M. Murofushi, M. Oki, K. Igarashi, J. Mochinaga, and Y. Iwadate $\mathrm{X}$-Ray Investigations on Molten $\mathrm{Cu}$-Sb Alloys

Th. Halm, H. Neumann, and W. Hoyer
An Effect of Urea on Association and Solvation of Ions in Aqueous Solutions of Alcohols

E. Hawlicka and T. Lis

Dielectric Properties of 4-Cyanobiphenyl in 1,4Dioxane Solution

S. v. Hornhardt, M. Stockhausen, J. Jadżyn, P. Kȩdziora, A. Ghoneim, and G. Turky X-Ray Diffraction Study on the Local Structure of Molten $\mathrm{ErCl}_{3}$. . . . . . . Y. Iwadate, T. Iida, K. Fukushima, J. Mochinaga, and M. Gaune-Escard An EXAFS Investigation of Local Structure around $\mathrm{Rb}^{+}$in Aqueous Solution

Y. Kubozono, A. Hirano, H. Maeda,

S. Kashino, S. Emura, and H. Ishida Molecular Dynamics in the System Methanoldimethylsulphoxide . . R. Ludwig, M. D. Zeidler, and T. C. Farrar A Geometrical Model of the Structure of Liquid Sil-
icon Incorporating the Local- and Medium-Range Orders . . . . . H. Ogawa, and Y. Waseda Ultrasonic Velocity and Absorption in $(\mathrm{Li}, \mathrm{Ag}) \mathrm{NO}_{3}$, $599 \quad(\mathrm{Na}, \mathrm{Ag}) \mathrm{NO}_{3}, \quad(\mathrm{~K}, \mathrm{Ag}) \mathrm{NO}_{3}, \quad(\mathrm{Cs}, \mathrm{Ag}) \mathrm{NO}_{3}, \quad(\mathrm{Li}$, $\mathrm{Rb}) \mathrm{NO}_{3}$, and (Na, Rb) $\mathrm{NO}_{3}$ Melts Measured by the Pulse Transmission Method

E. Rejek, J. Richter, A. Stark, and M. Vogt Chloride Ion in Liquid Hydroxylamine: Pair Potential Function and Monte Carlo Simulation

P. Sompornpisut, S. Kokpol, and B. M. Rode

Raman Scattering and X-ray Diffraction Studies on Zinc(II) Bromide Solutions in Methanol and N,N-Dimethylformamide in the Temperature Range 77-333 K . . . . T. Takamuku, K. Nakamura,
M. Ihara, H. Wakita, and T. Yamaguchi 
Dielectric Properties of 1-Hexanol in Mesitylene Solution on Admixture of Aromatic Dihydric Alcohols

G. Turky, F. F. Hanna, G. Klages, A. Ghoneim, and M. Stockhausen

Relation between NMR Properties and Electrical Resistivity in $\mathrm{Li}-\mathrm{Ge}, \mathrm{Li}-\mathrm{Sn}$ and $\mathrm{Li}-\mathrm{Pb}$ Liquid Alloys

R. Xu and W. van der Lugt

\section{Gaskinetik}

Temperature Dependence of the Second Dielectic Virial Coefficients of Rare Gases

M. O. Bulanin, U. Hohm, Yu. M. Ladvishchenko, and K. Kerl

\section{Hochfrequenzspektroskopie}

a) $E S R$

ESR of Gamma Irradiation Damage Centers in Single Crystals of Thrietanolamine Hydrochloride

M. Birey, H. Aktas, and D. M. Zengin Electron Paramagnetic Resonance of Some Irradiated Ammonium Compounds F. Köksal and M. Yavuz

\section{b) $N M R$}

The Rotational Spectrum of Tunnelling Methyl Groups . . . . . . . . . . . . S. Clough Molecular Motion in Solid Tetraethyl- and Tetrabutylammonium Perchlorates

B. Szafrańska and Z. Pająk

c) $N Q R$

Die NQR-Titel von Heft $1 / 2$ sind hier nicht aufgezählt, weil sie im Inhaltsverzeichnis (Seite III-VI) nach Sachen geordnet vorliegen.

The Bond $\mathrm{N}-\mathrm{Cl}$. Crystal Structures and ${ }^{35} \mathrm{Cl} \mathrm{NQR}$ of $\mathrm{N}-\mathrm{Cl}-\mathrm{N}$-Phenyl-2-chloroacetamine, N-Chloro$\mathrm{N}$-phenyl-2,2-dichloroacetamide, N-Chloro-N-phenyl2,2,2-trichloroacetamide, and N-Phenyl-2,2,2-trichloroacetamide . . . . Shi-qi Dou, B. T. Gowda,

$\mathrm{H}$. Paulus, and Al. Weiss ${ }^{79,81} \mathrm{Br}$ NQR Spectra of Alkyl(4-Bromophenyl)Sulphides . V.P. Feshin, P.A. Nikitin and I. A. Aliev Spatial Electron Density Distribution of Chlorine Atoms in Molecules of the Series $4-\mathrm{XC}_{6} \mathrm{H}_{4} \mathrm{MCCl}_{2}$ $\mathrm{C}(\mathrm{O}) \mathrm{C}_{6} \mathrm{H}_{5}(\mathrm{M}=\mathrm{S}$ and $\mathrm{Se})$. . . . V. P. Feshin, Y. E. Sapozhnikov, V. V. Shchepin, I. Yu. Petukhova, A. D. Gordeev, and G. B. Soifer The Bond $\mathrm{N}-\mathrm{Cl}$. A Spectroscopic $\left({ }^{35} \mathrm{Cl}-\mathrm{NQR}\right.$, IR) Investigation . . . . . B. T. Gowda and Al. Weiss ${ }^{35} \mathrm{Cl}$ and ${ }^{79} \mathrm{Br} \mathrm{NQR}$ Spectra in $\mathrm{Cp}_{2} \mathrm{M} \mathrm{Hal}_{2}$

S. I. Kuznetsov, E. V. Bryukhowa,

T. L. Khotsyanova, and G. K. Semin ${ }^{14} \mathrm{~N}$ Quadrupole Relaxation of DMF amd DMF-d in DMSO at Infinite Dilution

Xi-an Mao and M. Holz

${ }^{35} \mathrm{Cl}$ Nuclear Quadrupole Relaxation in Antimony Trichloride . . . . . . N. Okubo and Y. Abe Nuclear Quadrupole Resonance of Antimony in $\mathrm{Ln}_{3} \mathrm{Sb}_{5} \mathrm{O}_{12}$ Crystals . . . . . . A. M. Raevsky, A. G. Gukalova, and G. K. Semin ${ }^{121} \mathrm{Sb}$ and ${ }^{35} \mathrm{Cl} \mathrm{NQR}$ in $\mathrm{RCN} \cdot \mathrm{SbCl}_{5}$ Complexes

G. K. Semin, S. I. Kuznetsov, A. M. Raevsky, and E. V. Bryukhova

Phase Diagram, ${ }^{35} \mathrm{Cl} \mathrm{NQR}$, and Crystal Structure of 1-Chloro-2-methyl-2-chloromethylpropionic Acid ( $\beta, \beta^{\prime}$-dichloropivalic Acid), Phase II

R. Strauß, Shi-qi Dou, H. Fuess, and Al. Weiss
Nitrogen-14 SQUID NQR of L-Ala-L-His and of Serine . . . . . . U. Werner-Zwanziger, M. Ziegeweid, B. Black, and A. Pines

d) Mikrowellenspektroskopie

On the Validity of Additivity Rules for the Molecular Magnetizability Tensor and the Molecular $g$-Tensor in van der Waals Complexes. A Rotational Zeeman Effect Study of 1,1-Dideutero-Cyclopropane

O. Böttcher, V. Meyer, and D. H. Sutter Internal Rotation Analysis of the Ground State Microwave Spectrum of 2-Iodopropene J. Gripp and H. Dreizler

The ${ }^{33} \mathrm{~S}$ Nuclear Hyperfine Structure in the Rotational Spectrum of Isothiazole

J. Gripp, U. Kretschmer, and H. Dreizler Reanalysis of the Nuclear Quadrupole Coupling in the Rotational Spectrum of N-Methylpyrrole

S. R. Huber, A. Bauder, V. Storm, and H. Dreizler

Synthesis and Microwave Spectroscopic Study of Fluorinated Methyl Isocyanides M. Krüger, H. Dreizler, D. Lentz, and D. Preugschat

The ${ }^{\mathrm{r}} \mathrm{Q}_{2}$-branch of $\mathrm{HOOH}$ at $1.05 \mathrm{THz}$

A. F. Krupnov, S. P. Belov, G. Winnewisser, J. Behrend, M. Liedtke, R. Schieder, K. M. T. Yamada, and E. Herbst A Molecular Beam Fourier Transform Microwave Spectrometer in the Range 26.5 to $40 \mathrm{GHz}$. Tests of Performance and Analysis of the D- and ${ }^{14} \mathrm{~N}-\mathrm{Hyper}$ fine Stucture of Methylcyanide-d

I. Merke, W. Stahl, and H. Dreizler Double Modulation Technique in Pulsed Jet Experiments with Tunable Diode Lasers

I. Pak, M. Hepp, R. Philipp, R. Schieder, and $\mathrm{G}$. Winnewisser

Rotational Spectra of ${ }^{14} \mathrm{~N}^{17} \mathrm{O}$ and ${ }^{15} \mathrm{~N}^{18} \mathrm{O}$

A. H. Saleck, M. Liedtke, A. Dolgner, and $\mathrm{G}$. Winnewisser

On the Sign of the Off-Diagonal Elements of the Nuclear Quadrupole Coupling Tensor

U. Spoerel, H. Dreizler, and W. Stahl (N)

\section{Hydrodynamik}

Rayleigh-Taylor Instability of Newtonian and Oldroydian Viscoelastic Fluids in Porous Medium R. C. Sharma and V. K. Bhardwaj

\section{Isotopieeffekte}

Inverse Isotope Effect on the Melting Temperature of $\mathrm{LiNO}_{3}$. . . . . . . T. Hidaka and A. Lundén Theory of Linear Response Applied to the Lithium Isotope Effects on the Mobilities in Molten $\mathrm{LiCl}$

L. Schäfer and A. Klemm

Comments on H/D Isotope Effects on Polarizabilities of Small Molecules, Correlation with Virial Coefficient, Molar Volume, and Electronic Second Moment Isotope Effects

W. A. Van Hook and M. Wolfsberg

\section{Ionisierte Gase, Plasmaphysik}

A Simplified Algorithm for Finding Partially Invariant 630 Solutions of Quasilinear Systems . D.-A. Becker Effects of Finite Larmor Radius and Hall Currents on Thermosolutal Instability of a Partially Ionized Plasma in Porous Medium

K. Prakash and S. Manchanda 
Similarity Solutions of the Force-free Magnetic Field Equations . . . . . . . . . . . . E. W. Richter Hydromagnetic Kelvin-Helmholtz Instability in the Presence of Suspended Particles and Finite Larmor Radius Effect

R. K. Sanghvi and R. K. Chhajlani Finite Larmour Radius and Hall Effects on Thermal Instability of a Plasma in Porous Medium

R. C. Sharma and V. K. Bhardwaj

\section{Kern- und Elementarteilchenphysik}

The G-Band Systematics of Vibrational and Transitional Nuclei with $A=150$ to 166

M. I. El-Zaiki and H. E. Abdel-Baeth Search for an Admixture of a $17 \mathrm{keV}$ Neutrino in the $\beta$ Decay of ${ }^{35} \mathrm{~S}$. S. Müller, C. Shiping, H. Daniel, O. Dragoun, N. Dragounová, H. Hagn,

E. Hechtl, K.-H. Hiddemann, and A. Spalek A very Simple Mass Formula for the Masses of Pseudoscalar Mesons . . . . . . . . H. Otte (N) Non-Strange Baryon Resonances in the Isgur-Karl Model Including the $N=3$ Oscillator Shell S. Querbach and M. Kretzschmar No Decelerated $\beta$-Decay of Tritium Solved in Titanium . . . . . . . . . . . . . E. Wicke (N)

\section{Lumineszenz}

Spectral Properties of Some Naphthalene Derivatives of Bicarboxylic Acid; Comparison of Experimental Results with Theoretical Predictions

D. Bauman, T. Hanemann, and E. Wolarz The Influence of Reverse Nonradiative Excitation Energy Transfer on the Fluorescence Spectra of Twocomponent Fluorescent Solutions . . P. Bojarski, A. Kawski, B. Kukliński, and H. Dieh Molecular Properties of PPO Excimer Luminescence in a Binary Solvent . . . . . F. Burak, J. Tyrzyk, and Z. Polacki

Fluorescence of 8-(Phenylamino)-1-naphthalene-ammonium-sulfonate in Solvents of Different Polarity

S. H. Hüttenhain, W. Balzer, and R. Feldmann Fluorescence and Phosphorescence Anisotropy Spectra of Indole in Poly(Vinyl Alcohol) Film at Room Temperature . . . . A. Kawski, I. Gryczyński, and Z. Gryczyński (N)

Photoselection on Luminescent Molecules in Anisotropic Media in the Case of Two-Photon Excitation. Part I. Theoretical Considerations

A. Kawski and G. Piszczek Isomerization of Diphenyl Polyenes. Part VIII. Absorption and Fluorescence Properties of 1-Phenyl-4diphenylthiophosphinyl Butadiene in Poly(vinyl alcohol) Film A. Kawski, G. Piszczek, B. Kukliński, and T. Nowosielsk Influence of Silver Cations on the Fluorescence Properties of Polycyclic Aromatic Hydrocarbons

M. Komfort, J. Küster, and H. Dreeskamp Luminescence Spectra of the Mixed Chloro-BromoOsmates(IV), $\left[\mathrm{OsCl}_{n} \mathrm{Br}_{6-n}\right]^{2-}, n=1-5$

M. Manthey and W. Preetz

\section{Massenspektroskopie}

Mass Selected ZEKE-Spectra of $\mathrm{FeC}_{2}$-Anions: A Spectroscopic Access to Intermediates in Catalytic Reactions of Hydrocarbons on Metal Surfaces

G. Drechsler, C. Bäßmann, U. Boesl, and E. W. Schlag (N)

\section{Mikroskop}

902

1102

547
New Concept of a Scanning Laser Microscope Integrated Inside an Encapsulated Cryogenic Sample Stage . . . A. Kittel, A. Willmann, H.-G. Wener, R. Richter, R. P. Huebener, and J. Parisi (N)

\section{Moleküle, theoretisch}

The Three-Center, $\chi$-Electron Chemical Bond

M. S. de Giambiagi, M. Giambiagi, and J. Herrera Semiempirical Calculations for the Determination of the Conformation of 4,5-dihydro-1,3-dioxepine and its 2-methyl Derivative . J. Esser, J. Fleischhauer, H. Frauenrath, Ch. Jansen, B. Kramer, and J. Runsink

Wiener Number of Polyphenyls and Phenylenes I. Gutman and G. Dömötör Calculating the Determinant of the Adjacency Matrix and Counting Kekulé Structures in Circulenes

I. Gutman, Y.-N. Yeh, S.-L. Lee, H. Hosoya, and S. J. Cyvin

The Dependence of Vicinal Proton-Proton Coupling Constants on Molecular Structure

Z. Marković, S. Konstantinović, and I. Gutman Graph-Theoretical Enumeration of Conjugated Patterns for Carboxcylic and Heterocyclic Compounds T. Morikawa

Structural Features for Non-Existence of Conjugated Patterns for Carbocyclic and Heterocyclic Compounds . . . . . . . . . . . . . T. Morikawa Upper and Lower Bounds for the Number of Conjugated Patterns in Carbocyclic and Heterocyclic Compounds . . . . . . . . . . . . . T. Morikawa Isonumeric Compounds: Derivative Enumeration I. Novak

\section{Nichtlineare Dynamik}

Transition to Higher Chaos in Diffusively Coupled Chemical Oscillators . . . . . B. Baier, S. Sahle, U. Kummer, and R. Brock On Biharmonic Fractals Displaying a Structural Transition . . . . . . E. Canessa and W. Wang The Velocity of Current Filaments in Weak Magnetic Fields . . . . . . . . . . . . . T. Christen Nonequilibrium Phase Transition and Current Filaments in Extrinsic Semiconductors . . T. Christen Universality in the One-Dimensional Self-Organized Critical Forest-Fire Model . . B. Drossel, S. Clar, and F. Schwabl

NMR Field-Cycling Study of Rotational Flow and Viscosity in Nematic Liquid Crystals . H. Gotzig, S. Grunenberg-Hassanein, and F. Noack Linear Scaling Laws in Bifurcations of Scalar Maps C. Grebogi

The Influence of Noise on Fractals . . A. Hamm Chaos Control and Neural Classification

Bifurcations on Globally Coupled Shift Maps A A. Hoff W. Just

Delayed Feedback Control of Chaos in an Electronic Double-Scroll Oscillator . . . A. Kittel, J. Parisi, K. Pyragas, and R. Richter Hierarchic Analysis of Chaotic Scattering in Reactive Collisions . . . . . Z. Kovács and L. Wiesenfeld On the Relation between Statistics of Scalar and Velocity Fluctuations in Developed Turbulence J. Peinke and B. Castaing 
A Generalized Kac Model as a Dynamical System

Á. Péntek, Z. Toroczkai, D. H. Mayer, and T. Tél Mechanisms for Phase Transitions in the Multifractal Analysis of Invariant Densities of Correlated Random Maps . . . . . . . . . . . . G. Radons Time-Averaged Quantity of a Low-Temperature Semiconductor Experiment Reflects Scaling Behavior of Saddle-Node Bifurcation to Chaos

R. Richter, A. Kittel, and J. Parisi

Noisy Maps near Crises . . . . . . P. Reimann The 'Triptych Fractal' - A New Feature of the Logistic Map . . . . . . . R. Richter, C. A. Kruelle, A. Kittel, and O. E. Rössler Extended Lorenz Models and Time Dependent First Integrals . . . . . . . . . . . . W.-H. Steeb Entropic Characterisation of Diffusion

R. Stoop and W.-H. Steeb Constrained Frobenius-Perron Operator to Analyse the Dynamics on Composed Attractors

K. G. Szabó and T. Tél The Topological Entropy for an Inclined Billiard in a Gravitational Field . . . . . . . . J. Vollmer From Dispersion to Laminarity in Dynamical Systems . . . . . . G. Zumofen, J. Klafter

\section{Oberflächen}

Dispersion Potentials between Atoms and Dielectric Bodies . . . . . . . . . . . . . . F. Schuller

\section{Orthogonale Polynome}

Small Oscillations, Sturm Sequences, and Orthogonal Polynomials . . . . . . . . . . M. Baake

\section{Phasenumwandlungen}

Orientational Order-Disorder and Phase Transition in Solid Trichloromethane Sulfonic Acid Chloride, $\mathrm{Cl}_{3} \mathrm{CSO}_{2} \mathrm{Cl}$. . . . . Shi-qi Dou, H. Fuess, W. Schmahl, R. Strauss, and Al. Weiss Phase Transitions in $\mathrm{M}^{\mathrm{II}} \mathrm{TiF}_{6} \cdot 6 \mathrm{H}_{2} \mathrm{O}(\mathrm{M}=\mathrm{Cd}, \mathrm{Zn}$, Co): An EPR Study . . . . . . . G. Jayaram Detecting Phase Transitions in Intermittent Systems by Using the Thermodynamical Formalism

Z. Toroczkai and Á. Péntek The Dielectric and Dilatometric Single Crystal Studies of Phase Transitions in a New Member of Family of Halogenoantimonates(III) $\left[\mathrm{C}\left(\mathrm{NH}_{2}\right)_{3}\right]_{2} \mathrm{SbCl}_{5}$. $\left[\mathrm{C}\left(\mathrm{NH}_{2}\right)_{3}\right] \mathrm{Cl}$. . . . . J. Zaleski and R. Jakubas Crystal Structure and Phase Transitions of $\left[\mathrm{C}\left(\mathrm{NH}_{2}\right)_{3}\right]_{3} \mathrm{Sb}_{2} \mathrm{Cl}_{9} \cdot 0.9 \mathrm{H}_{2} \mathrm{O}$

J. Zaleski and A. Pietraszko

\section{Photochemie}

Flash Photolysis Studies of 4-Chloroanisole in Aqueous Solution . . F. S. M. Abd El-Hameed, P. Krajnik, and N. Getoff
Radiation Induced Incorporation of $\mathrm{CO}$ in Pure and Aqueous Methanol . . . . H.-J. Jung, N. Getoff, and E. Lorbeer

Photoionization of $\mathrm{C}_{60}$ and $\mathrm{C}_{70}$ in Liquid Alkanes R. Katoh, K. Lachmann, and W. F. Schmidt

\section{Quanten- und Relativitätstheorie}

Scalar Potentials and the Dirac Equation

B. Bergerhoff and G. Soff

Effective Boson-Fermion Dynamics for Subfermion Models . . . . . . . . . . . . . . G. Grimm

Exact Solution Of Two Body Dirac Equations N. Nag and R. Roychoudhury

751 Solving the Schrödinger-Equation as a One-Dimensional Problem. I. The Formalism . . H. Preuss Light Propagation in a Curved-Space Friedmann Universe . . . . . . . . . . S. J. Prokhovnik and A. E. Paparodopoulos Some Algebraic Properties of Maxwell-Dirac Isomorphism . . . . . . . . . . . . . V. Simulik 861 Statistical Mechanical Interpretation of Black Hole Entropy . . . . . . . . . . . . F. Winterberg

\section{Reaktionskinetik}

A Molecular Source of $\mathrm{CF}_{2}(\tilde{\mathrm{X}})$ at Room Temperature . . . . . W. Hack and M. Wagner $(\mathrm{N})$

885 Polymer Crystallization as the Self-Organization of Chain Macromolecules

A. I. Melker and T. V. Vorobyeva Coupled Bistable Chemical Systems - Experimental Realization of Boolean Functions Using a Simple Feedforward Net . . . K.-P. Zeyer, G. Dechert, W. Hohmann, R. Blittersdorf, and F. W. Schneider

\section{Seladon}

Provenance Study of Famous Chinese Greenware Bodies Using Principal Component Analysis

C. T. Yap and Y. Hua

\section{Supraleiter}

Kinetics and Mechanism of $\mathrm{Nd}_{2} \mathrm{CuO}_{4}$ Synthesis P. Ghigna and M. Scavini

\section{Tomographie}

A Model Study of Electrical Impedance Tomography Using Synthetic Finite Precision Data

B. Buchert and K. Schilcher

\section{Wärmekraftmaschine}

The Concept of a Novel Heat Engine . H. Daniel 1037

\section{Erratum}




\section{Authors Index}

Die Seitenzahlen von Originalarbeiten und Notizen sind im Steildruck, diejenigen der übrigen Beiträge sind kursiv gesetzt.

Abdel-Baeth, H. E. 802

Abd El-Hameed, F. S. M. 515

Abe, Y. 680

Ackermann, H. 27, 354

Ainbinder, N. E. 425

Aktas, H. 946

Aliev, I. A. 639

Amstutz, N. 199

Ankele, J. 771

Asaji, T. 253

Baake, M. 445, 1262

Bäßmann, C. 1256

Baier, G. 853

Bakó, I. 967

Baldus, M. 80

Balzer, W. 1087

Bastow, T. J. 320

Bauder, A. 1063

Bauman, D. 671

Becker, D.-A. 458

Behrend, J. 525

Belov, S. P. 525

Bergerhoff, B. 997

Bernadelli, G. 193

Bettinelli, M. 977

Bhardwaj, V. K. 547, 927

Bilal, B. A. 939,943

Birey, M. 946

Blaha, P. 129

Blair-Fish, J. A. 137,146

Blank, H.-R. 361

Blasberg, T. 14

Blinc, R. 31, 329

Blittersdorf, R. 953

Blümich, B. 19

Boesl, U. 1256

Bojarski, M. 42, 931

Bondarev, I. V. 439

Böttcher, O. 585

Bray, P. J. 65

Brinkmann, D. 389

Brock, R. 835

Brown, R. J. C. 302

Brückert, T. 552

Bryukhova, E. V. 627,630

Buchert, R. 920

Buhl, J.-Ch. 1171

Bulanin, M. O. 890

Burak, F. 964

Bush, A. A. 425

Canessa, E. 819

Castaing, B. 831

Chen, J.-J. 1013

Chhajlani, R. K. 1102
Christen, T. 847,851

Chrzanowska, A. 635

Clar, S. 856

Clarke, J. 5

Clough, S. 1193

Cormier, G. 977

Cyvin, S. J. 1053

Czechowski, G. 1077

Daniel, H. 874,1037

Dechert, G. 953

Dey, M. 776

Diehl, H. 354, 931

Dierking, I. 1081

Dimitropoulos, C. 232

Dmitrichenko, M. Yu. 171

Dolgner, A. 1111

Dolgushin, G. V. 167, 171

Dolinšek, J. 329

Dömötör, G. 1040

Dou, S. 174, 202, 213, 223, 594, 1136, 1145

Dragoun. O. 874

Dragounová, N. 874

Drechsler, G. 1256

Dreeskamp, H. 578

Dreizler, H. 490, 497, 645, 703, 1059, 1063

Drossel, B. 856

Du, M.-L. 1013

Dufek, P. 129

Dufner, H. 116

Dworschak, F. 391

Eguchi, T. 267

El Ghallali, J. 433

El-Zaiki, M. I. 802

Emura, S. 727

Erata, T. 247, 291

Eremin, M. V. 379,385

Esser, J. 709

Fam, S. H. 425

Farrar, T. C. 1131

Feldmann, R. 1087

Feshin, V.P. 522, 639

Fischer, B. 354

Fleischhauer, J. 714

Forte, C. 311

Fowler, P. W. 125

Frank, H.-P. 354

Frank, M. 361

Frantz, G. 116

Frauenrath, H. 714

Fuess, H. 174, 594, 1145

Fujino, T. 1031

Fukushima, K. 785, 811
Furman, G. B. 97

Furukawa, Y. 247, 258

Gaune-Escard, M. 811

Geiger, M. 361

Geppi, M. 311

Getoff, N. 515, 617

Ghigna, P. 611

Ghonheim, A. 503, 949

Giambiagi, M.S. de 754

Giambiagi, M. 754

Giesselmann, F. 1081

Gippius, A. A. 425

Goldbach, A. 1067

Gordeev, A. D. 522

Gotzig. H. 1179

Gourdji, M. 433

Gowda, B. T. $\quad 695,1136$

Grebogi, C. 1207

Greneche, J.-M. 361

Grimm, G. 649

Gripp, J. 497, 1059

Groke, D. 599

Grothemeyer, J. 776

Grunenberg-Hassanein, S. 1179

Gryczyński, Z. 1091

Gryczyński, I. 1091

Guibé, L. 433

Guilpin, Ch. 663

Gukalova, A. G. 687

Gutman, I. 815, 1040 , 1053

Haas, H. 407

Hack, W. 730

Hagn, H. 874

Halm, Th. 530

Hamagawa, T. 401

Hamm, A. 1238

Hanemann, T. 671

Hanna, F. F. 503

Hashimoto, M. 273, 279

Hattori, M. 291

Hattori, M. 291

Hawlicka, E. 623

Hechtl, E. 874

Heger, G. 599

Heinzinger, K. 967

Heitjans, P. 27

Hellemans, L. 1077

Hensel, F. 1067

Hepp, M. 913

Herbst, E. 525

Herrera, J. 754

Hetscher, M. 1165

Hidaka, T. 475
Hiddemann, K.-H. 874

Hilmer, F. 27

Hirano, A. 727

Hoff, A. A. 589

Hoffmann, W. 1171

Hohm, U. 890

Hohmann, W. 953

Holz, M. 1016

Honda, H. 209, 247

Hook, W. A. van 563

Horiuchi, K. 286

Hornhardt, S. von 949

Hosoya, H. 1053

Hoyer, W. 530

Hua, Y. 759

Huber, H. 103

Huber, S. R. 1063

Huebener, R. P. 642

Hüttenhain, S. H. 1087

Igarashi, K. 785

Ihara, M. 1119

Iida, T. 811

Ikeda, R. 247, 253, 291, 723

Ishida, H. 723. 727

Ishihara, H. 213

Ishikawa, A. 209

Ismaier, M. 361

Isobe, K. 258

Ittermann, B. 354

Iwadate, Y. 785,811

Jacob, K. T. 1031

Jadżyn, J. 949, 1077

Jäger, E. 354

Jagličić, Z. 367

Jakubas, R. 709

Jansen, Ch. 714

Jayaram, G. 535

Jung, H.-J. 617

Just, W. 1233

Kajitani, T. 401

Kaltenhäuser, M. 361

Kanert, O. 1151

Kapp, R. 361

Kashino, S. 723, 727

Katoh, R. 793

Kawski, A. 824, 931, 936, 1091

Kȩdziora, P. 949

Kelly, H. M. 125

Kenmotsu, M. 247

Kerl, K. 890

Khotsyanova, T. L. 627

Kieninger, M. 391 
Kimmich, R. 35

Kinoshita, Y. 185

Kittel, A. 642, 838, 843, 871

Klafter, J. 1241

Klages, G. 503

Klemm, A. 1251

Kohlsmann, S. 1165

Kokpol, S. 797

Köksal, F. 1159

Komfort, M. 578

Konstantinović, S. 815

Konzelmann, K. 47

Koto, K. 202

Kovács, Z. 1229

Krajnik, P. 515

Kramer, B. 714

Kramer, K. 1165

Kravchenko, E. A. 418, 425

Kreische, W. 361

Kretschmer, U. 1059

Kretzschmar, M. 733

Krishnan, M.S. 71

Krishnan, V. G. 213, 223

Kruelle, C. A. 871

Krüger, M. 703

Krupnov, A. F. 525

Kubozono, Y. 723, 727

Küchler, R. 1151

Kuczynski, W. 1081

Kukliński, B. $\quad 824,931$

Kummer, U. 835

Kunimoto, M. 279

Küster, J. 578

Kuten, S. A. 439

Kuznetsov, S. I. 627,630

Kyan, H. 401

Lacmann, K. 793

Ladvishchenko, Yu. M. 890

Lamparter, P. 771

Larina, L. I. 167

Lazarev, I. M. 167

Leblanc, M. 361

Lee, S.-L. 1053

Legrand, C. 1077

Le Noc, L. 373

Lentz, D. 703

Levante, T. O. 80

Li, Z.-M. 1013

Liedtke, M. 111, 525

Lis, T. 623

Löns, J. 1171

Lopyrev, V. A. 167

Lorbeer, E. 617

Lossen, U. 361

Lucken, E. A. C. 133,155 , 193, 199

Ludwig, R. 1131
Lugt, W. van der 1019

Lundén, A. 475

Lužnik, J. 367

Maćkowiak, M. 42

Maeda, H. 727

Majer, G. 47, 391

Mali, M. 389

Man, P. P. 89

Manchanda, S. 469

Manthey, M. 767

Marino, R. A. 65

Markendorf, R. 379, 395

Marković, Z. 815

Marti, C. Ch. 663

Matsubara, E. 1031

Matsumoto, S. 279

Matsuura, H. 690

Mayer, D. H. 1212

Mayer, J. 771

Medda, M.P. 977

Meier, B. H. 80

Melker, A. I. 1045

Merke, I. 490

Meyer, V. 585

Miyagi, K. 209

Mochinaga, J. 785, 811

Mohr, K. 1081

Mori, Y. 209

Morikawa, T. 511, 719, 973

Mosel, B. D. 1200

Müller, E. 939, 943

Müller, S. 874

Mundus, C. 1171

Murofushi, M. 785

Mykhalyov, K. N. 373

Nag, N. 983

Nakamura, N. 267, 337

Nakamura, K. 1119

Nakayama, H. 267

Neumann, H. 530

Niki, H. 273, 279, 401

Nikitin, P. A. 171, 639

Noack, F. 1179

Notter, M. 47

Novak, I. 790

Nowosielski, T. 824

Odahara, H. 273, 279, 401

Ogawa, H. 987

Ohki, H. 247, 291

Okada, I. 690

Oki, M. 785

Okubo, N. 680

Okuda, T. 185, 202, 258

Omori, M. 401

Onoda, Y. 291

Orlov, V.G. 418
Osipenko, A. N. 425

Ostafin, M. 42

Otte, H. 829

Pająk, Z. 465

Pak, I. 913

Pálinkás, G. 967

Palmer, M. H.' 137, 146

Paparodopoulos, A. E. 543

Parisi, J. 642, 838, 843

Paulus, H. 174, 1136

Pegelow, U. 1200

Peinke, J. 831

Peirson, N. F. 345

Pelzl, J. 232

Péneau, A. 433

Péntek, Á. 1212, 1235

Petersen, G. L. 65

Petukhova, I. Yu. 522

Philipp, R. 913

Piccaluga, G. 977

Pietraszko, A. 895

Pinna, G. 977

Pirnat, J. 367

Pisipati, V. G. K. M. 559

Piszczek, G. 824, 936

Polacki, Z. 964

Potukuchi, D. M. 559

Prakash, K. 469

Preetz, W. 767

Preugschat, D. 703

Preuss, H. 746

Prokhovnik, S. J. 543

Pusiol, D. 35

Pyragas, K. 843

Querbach, S. 733

Rademann, K. 1067

Radons, G. 1219

Raevsky, A. M. 630, 687

Ramaprabhu, S. 193, 199

Rani, G. P. 559

Rao, N. V.S. 559

Reimann, P. 1248

Rejek, E. 481

Richter, E. W. 902

Richter, J. 481

Richter, R. 642, 838, 843, 871

Robert, H. 35

Rode, B. M. 797

Rommel, E. 35

Roos, J. 389

Rössler, O. E. 871

Roychoudhury, R. 983

Rozinov, V. G. 171

Runsink, J. 714

Sahle, S. 835

Saito, M. 1031
Saleck, A. H. 1111

Sanctuary, B. C. 71

Sanghri, R. K. 1102

Sapozhnikov, Yu. E. 171, 522

Sasane, A. 209

Sato, N. 1031

Scavini, M. 611

Schäfer, L. 1251

Schieder, R. 525, 913

Schilcher, K. 920

Schirmer, A. 27

Schlag, E. W. 776, 1256

Schmahl, W. 594

Schmalz, M. 1200

Schmidt, P. C. 116

Schmidt, W. F. 793

Schneider, F. W. 953

Schöllhorn, R. 1200

Schuller, F. 885

Schwabl, F. 856

Schwarz, K. 129

Schweiss, B. P. 599

Seeger, A. 47, 391

Seelinger, W. 354

Seliger, J. 31

Semin, G. K. 627, 630, 687

Sharma, R. C. $\quad 547,927$

Shchepin, V. V. 522

Shinohara, T. 401

Shiping, C. 874

Simulik, V. 1074

Smith, J. A. S. $\quad 345,351$

Smith, M. E. 291

Soff, G. 997

Soifer, G. B. 522

Sokalski, K. 635

Solovjanov, S. G. 379

Sompornpisut, P. 797

Soulayman, S. Sh. 663

Špalek, A. 874

Spoerel, U. 645

Stahl, W. 490, 645

Stark, A. 481

Steeb, S. 771

Steeb, W.-H. 751, 1215

Stephenson, D. 345, 351

Stockhausen, M. 503, 949, 1077

Stöckmann, H.-J. 27, 354

Stoop, R. 1215

Storm, V. 1063

Strauß, R. 1145

Strauss, R. 594

Sulzer, G. 354

Suter, D. 14

Sutter, D. H. 585

Szabo, A. J. 302

Szabó, K. G. 1223

Szafrańska, B. 465 
Takamuku, T. 1119

Tamaki, K. 273, 279

Tasaki, A. 247

Tél, T. 1212,1223

Terao, H. 185, 202

Tomiyoshi, S. 401

Tomizawa, H. 253

Toroczkai, Z. 1212, 1235

Trokiner, A. 373

Trontelj, Z. 367

Turky, G. 503, 949

Tyrzyk, J. 964

Urban, S. 552

Veracini, C. A. 311

Verkhovskii, S. V. 373
Vielsack, G. 129

Vogt, M. 481

Volgina, G. A. 425

Vollmer, J. 861

Vorobyeva, T. V. 1045

Voronkov, M. G. 167 , 171

Wagner, M. 730

Wakeshima, M. 1031

Wakita, H. 1119

Wang, W. 819

Waseda, Y. 987, 1031

Watterich, A. 1151

Weber, W. 129

Wegener, J. 1151
Weiss, Al. 174, 202, 213, 223, 594, 599, 695, 1136, 1145

Wener, H.-G. 642

Wicke, E. 1259

Wiesenfeld, L. 1229

Willmann, A. 642

Winnewisser, G. 525, 913, 1111

Winterberg, F. 1023

Winterer, M. 1200

Wolarz, E. 671

Wolfsberg, M. 563

Würflinger, A. 552

Xi-an Mao 1016

Xu, R. 1019
Yakubowskii, A. 373

Yamada, K. 185, 258

Yamada, K. M. T. 525

Yamaguchi, T. 1119

Yap, C. T. 759

Yavuz, M. 1159

Yeh, Y.-N. 1053

Žagar, V. 31

Zalar, B. 329

Zaleski, J. 709, 895

Zapf, B. 361

Zaschke, H. 1081

Zeidler, M. D. 1131

Zengin, D. M. 946

Zeyer, K.-P. 953

Zugenmaier, P. 1081

Zumofen, G. 1241 
